\title{
ENTRE CALVOS ANDA EL JUEGO: LA INSISTENCIA DE UN TEMA SATÍRICO EN ROJAS ZORRILLA
}

\author{
GERMÁN VEGA GARCÍA-LUENGOS \\ Universidad de Valladolid
}

\section{RESUMEN}

Las sátiras contra calvos se intensificaron en la época barroca al compás que lo hizo el género. Las condición de tal de Francisco de Rojas Zorrilla no le impidió utilizar el motivo satírico con más desenfado que el que se aprecia en otros escritores afectados. Y con más insistencia: es el dramaturgo del siglo XVII del que más referencias a calvos se han localizado (en términos absolutos y relativos): 17 pasajes correspondientes a 13 comedias. Todas esas menciones tienen un carácter jocoso. Es inevitable considerar cuál es su grado de acatamiento o de desvío con respecto a la tradición satírica. Por otro lado, estas bromas apuntan aspectos interesantes de la actitud vital del escritor, de sus relaciones con los colegas y el público en general. La existencia y las características de estas alusiones burlescas también pueden servir de indicios en las tareas de atribución de comedias dudosas.

Palabras clave: Rojas Zorrilla. Comedias. Sátiras. Burlas. Calvos.

\section{ABSTRACT}

Satires against bald men intensified in early modern Spain as the genre developed. As a bald man himself, Francisco de Rojas Zorrilla used the motif with less seriousness than some other writers suffering from the same condition. He also used it more frequently, as he is the playwright of the time that has left us more examples, no less than 17 cases spread over 13 plays, all of them with a burlesque purpose. In all cases, his jokes on bald men say about his persona as much as about his relations with his peers, as well as with the audience in general. Ultimately, some of these satirical uses could be useful in tracing his name behind some texts of dubious authorship

Key Words: Rojas Zorrilla. Plays. Satirical uses. Burlesque. Bald men.

Al comienzo de la segunda jornada de Las paredes oyen (1616-1617), el gracioso Beltrán reprocha a su amo don Juan que haya desaprovechado una excelente oportunidad de endilgar una extensa relación de la fiesta de toros de Alcalá ${ }^{1}$ :

¿Por qué, señor, no has pintado

caballos, toros y suertes?

${ }^{1}$ Cito por Obras completas de Juan Ruiz de Alarcón. Ed. de A. Millares Carlo, México, Fondo de Cultura Económica, 1957-1968, I, p. 295. 
Que con eso, y con tratar mal a los calvos, hicieras comedias con que pudieras tu pobreza remediar.

(vv. 1180-1197)

Es evidente que los calvos constituían uno de los grupos de riesgo satírico mejor definidos en la vida y la literatura de los Siglos de Oro. De los versos antedichos de Ruiz de Alarcón podría inferirse incluso que el tema se llevó la palma sobre cualquier otro $^{2}$. Y eso que aún faltaban varios años para que iniciase su carrera como escritor el toledano Francisco de Rojas Zorrilla, que es el dramaturgo del siglo XVII del que más referencias a calvos he localizado en sus comedias, tanto en cifras relativas como absolutas. De su condición de tal nos han llegado noticias propias y de sus contemporáneos. El contexto que se trasluce de dichos testimonios incita a concebir los chistes de calvos en que incurren los personajes de sus obras como prolongación del ambiente jocoso de las academias en las que participaba. Adelantarse a las risas de los demás con la burla de uno mismo es un mecanismo psicológico bien efectivo y conocido ${ }^{3}$. Anécdotas como las que se recordarán más adelante muestran que lo practicaba en los cenáculos con sus colegas. En los tablados muy probablemente el auditorio se lo tomaría como un gesto de complicidad. La insistencia con que en unos pocos años Rojas utilizó ese tema da pie para pensar que era un guiño, cuya eficacia estribaría en que los espectadores en general - mejor que sólo los colegas de escritura dramática y academias - identificaran al escritor. Aspectos como éste pueden valer también para considerar que la enorme maquinaria comercial en que se convirtió ese fenómeno de masas que fue el teatro no habría conseguido desdibujar la personalidad de los creadores, capaces de mantener formas de sintonía directa con su público

Esta propensión también pudiera servir como un indicio - que habrá que juntar con bastantes otros- para la adscripción de las comedias dudo-

${ }^{2}$ Los sondeos realizados en comedias conservadas de los años previos a 1616-1617, que es la franja propuesta para la comedia susodicha (ibíd., p. 256), no muestran, desde luego, que tenga la frecuencia que da a entender el escritor mexicano, que quizá sea, precisamente, el dramaturgo que con mayor insistencia alude a los calvos en esos años, con intención - bien es de creer- de intercambiar pullas sobre defectos físicos con su rival Cristóbal Suárez de Figueroa (para las relaciones encontradas de ambos escritores, ver Willard F. KING, Juan Ruiz de Alarcón, letrado y dramaturgo. Su mundo mexicano y español, México, El Colegio de México, 1989, pp. 166-170). Sobre ellos vuelve Alarcón en el acto tercero de esa misma obra (vv. 2508-2512); antes lo había hecho en El semejante a sí mismo (1611-1614) (vv. 21-24), y después en La prueba de las promesas (h. 1618) (vv. 2035-2046) y El Anticristo (1623) (vv. 2227-2246). Lo que no son pocas alusiones para un repertorio de dimensiones contenidas.

3 También Ruiz de Alarcón hacía chanzas sobre su físico. Ver K. C. SMYTHE DE URquiEtA, The Seventeenth Century Image of the Spanish Dramatist Juan Ruiz de Alarcón, Ann Arbor, UMI, [1988]. 
sas que presenta su repertorio ${ }^{4}$. Como tal lo utilicé en el estudio de autoría de Más vale maña que fuerza, una de las obras dadas por perdidas.

\section{ROJAS ZORRILLA, POETA CALVO}

La convivencia del dramaturgo con sus colegas tuvo un campo especial de desarrollo en las academias, que en ocasiones quedó reflejada en relaciones y vejámenes. Estos escritos nos muestran algunos aspectos de la consideración que mereció de los otros y de sí mismo, siempre teniendo en cuenta el tono jocoso de las sesiones ${ }^{6}$. Destacan como rasgos de su prosopografía el tamaño de sus pies, su suciedad y su calvicie, cubierta no siempre con una cabellera. De su etopeya, merece la pena destacar su humor, que no duda en dirigir contra sí mismo. Repasemos algunos testimonios conocidos. En la Academia burlesca que se celebró en el Buen Retiro el 15 de febrero de 1637 hay una intervención del propio escritor que dice:

Venía don Pedro Calderón en medio, probándose a un espejo mi cabellera, pero, viendo que no le asentaba, la arrojó diciendo así:

No me la quiero poner,

que a mi desgracia recelo

que no la ha de cubrir pelo ${ }^{7}$.

${ }^{4}$ Ver «La delimitación problemática del repertorio de Rojas Zorrilla» en Rafael GonZÁlez CAÑAl, Ubaldo CEREZo Rubio y Germán Vega García-Luengos, Bibliografía de Francisco de Rojas Zorrilla, Kassel, Edition Reichenberger, 2007, pp. 3-8.

${ }^{5}$ Germán Vega García-LuENGos, «Más vale maña que fuerza: Los enredos albaneses de una comedia desconocida atribuida a Rojas Zorrilla», en Felipe PEDRAZA JiMÉNEZ, Rafael GonZÁlez CAÑAl y Elena MARCEllo, eds., Francisco de Rojas Zorrilla, poeta dramático. Actas de las XXII Jornadas de Teatro Clásico. Almagro, 13, 14 y 15 de julio, Almagro, Festival de Almagro-Universidad de Castilla-La Mancha, 2000, pp. 55-87.

${ }^{6}$ Precisamente en el caso de Rojas hay alguna noticia que apuntaría a que no siempre fueron pacíficas sus consecuencias. En unos Avisos manuscritos custodiados en la Biblioteca Nacional se lee que el 24 de abril de 1638 ocurrió la «desgraciada muerte» del poeta «alevosamente, sin que haya podido penetrar la causa del homicidio» (en Emilio Cotarelo y Mori, Don Francisco de Rojas Zorrilla. Noticias biográficas y bibliográficas, Madrid, Imprenta de la Revista de Archivos, 1911, p. 61). Casi un mes más tarde se apunta el rumor de que su fallecimiento fue a causa del Vejamen realizado en el Palacio de Buen Retiro por Carnaval, «de donde quedaron algunos caballeros enfadados con el dicho». Está claro que no murió de esas heridas, si es que las hubo.

${ }^{7} \mathrm{La}$ academia ha sido bien editada y estudiada recientemente por M. ${ }^{a}$ Teresa JuLIO, Academia burlesca que se hizo en Buen Retiro a la Majestad de Filipo Cuarto el Grande Año de 1637, Pamplona-Madrid-Frankfurt am Main, Universidad de Navarra-Iberoamericana-Vervuert, 2007, p. 228. 
En un vejamen posterior de Rojas se lee ${ }^{8}$ :

Y como para ser San Pedro no me faltaba más que ser calvo, me quité la cabellera [...] «¿Quién eres?», le dije asombrado; a lo que el indeterminado bulto respondió: «¿No me espanto yo de verte sin cabellera, y te asombras de verme a mí con ella?» ... Llegóse en esto a mí Solís y me dijo: «¿No sabes, amigo, que me han contado que Coello nos trata da puercos en su vejamen ${ }^{9}$ ?

Hacia 1640, según E. Cotarelo, Jerónimo de Cáncer escribió en otro vejamen:

Volví la cara y vi venir a un hombre que se las pelaba por caminar apriesa. Traía, a mi parecer, la cabeza colgada de la pretina y sobre los hombros una calabaza. Parecióme extraño el modo de caminar; y acercándome más, conocí que era don Francisco de Rojas, que la priesa no le había dado lugar de ponerse la cabellera, y al pasar junto a mí, le dije:

La priesa al revés te pinta;

hombre, para caminar,

yo siempre he visto llevar

la calabaza a la cinta ${ }^{10}$.

Por lo que se aprecia, su condición de calvo no le impedía utilizar el tema satírico con más desenfado que el que parece traslucirse de otros poetas afectados. Rojas no sólo no les hizo feos a los chistes de calvos sino que debió de usarlos como antidepresivo y como escudo contra las pullas de sus congéneres, tanto en las academias como en sus obras dramáticas. En algunas de éstas hay personajes que riman bastante bien con esa imagen que configuran los testimonios vistos. Todo apunta a que son autorretratos jocosos perpetrados con premeditación y alevosía. El más conocido, por la importancia de la obra, es el caso de don Lucas del Cigarral, el protagonista de Entre bobos anda el juego (texto 4 del apartado siguiente). Recuérdese cómo al comienzo de la pieza el gracioso, que se llama precisamente Cabellera, tras presentarse a Isabel y hacer alguna broma con su nombre, describe a su amo don Lucas, entre cuyas características está la de ser «calvo un poco», amén de otras tachas, como tener «los pies un poquillo luengos» y ser «cuarenta muchos puerco». En opinión de M. G. Profeti, se trata de «una descripción extremada y excesiva, un autorretrato de caricatura con el cual Rojas intenta superar rencillas y sinsabores para

${ }^{8}$ Fue presentado en otra academia de una semana después, según sus descubridor y editor, Manuel Serrano y Sanz (Apéndice a L. VÉlez DE GuevarA, El diablo cojuelo, Vigo, Krapf, 1902, pp 262-271), o al año siguiente como quiere Emilio Cotarelo (op. cit., p. 58).

9 En F. DE Rojas Zorrilla, Entre bobos anda el juego. Edición y estudio preliminar de Maria Grazia Profeti, Barcelona, Crítica, 1998, p. XXXIV. Las citas de la comedia se harán por esta edición.

${ }^{10}$ Op. cit., p. 50. 
decir a su público que conoce bien sus defectos físicos y que incluso está dispuesto a burlarse de ellos» ${ }^{11}$.

Y no sería la única vez que en el teatro conservado del escritor se pinta a un personaje con rasgos jocosos semejantes a los que los vejámenes de la época ofrecen de él. Creo que tampoco estaría lejos el don Melchor de Sin honra no hay amistad, tal como lo describe el gracioso Sabañón en la segunda jornada (texto 2). Éste le cuenta que doña Juana, la dama a la que pretende, se burla de él diciendo por ahí, entre otras cosas, que es «calvo, sin modestia», porque anda sin cabellera, con la «calva a la vergüenza»; y que con sus «dos pies se entienden los medidores de leguas».

La calva en estas dos ocasiones es un factor negativo entre otros que retratan a un personaje ridículo. Es frecuente en la literatura burlesca de la época la mención de sujetos que combinan diversos defectos físicos: jorobados, zambos, tuertos, zurdos, calvos ${ }^{12}$.

\section{Los textos CON ALUSIONES A CALVOS EN EL TEATRO DE ROJAS ZORRILLA}

Son diecisiete los fragmentos que contienen las menciones localizadas, correspondientes a trece comedias distintas. Se han dispuesto por el orden en que aparecen en las dos partes del dramaturgo (cuyas primeras ediciones son de 1640 y 1645), y se han dejado para el final los que se incluyen en las que no se publicaron en ellas. Cuando se considere necesario para comprender mejor el sentido de la alusión, se antepondrá una breve presentación del contexto. Será en el apartado siguiente cuando se comenten conjuntamente los aspectos más notables de los diferentes casos.

\section{Casarse por vengarse}

Fue publicada en cuarto lugar de la Primera parte (1640). Figuraba ya entre las ocho comedias que el escritor vendió en marzo de 1635 al librero Diego Logroño ${ }^{13}$, por lo que cabría pensar que la fecha de escritura es al menos cuatro o cinco años anterior. El diálogo que interesa lo mantienen amo y criado en la primera jornada ${ }^{14}$ :

${ }_{11}$ Op. cit., p. XXXV.

12 Para este y otros aspectos de las burlas contra calvos en el siglo XVII, véase Germán Vega GARCía-LuEngos, «El tratamiento (satírico) de la calvicie en el siglo XVII español», Homenaje al Profesor Anthony Close, Alcalá de Henares, Centro de Estudios Cervantinos [en preparación].

13 Alejandro RUBIO SAN ROMÁn y Elena MARTíneZ CARRO, «Aportación documental a la obra de Rojas Zorrilla», Dicenda. Cuadernos de Filología Hispánica, 24 (2006), pp. 219-234.

${ }^{14}$ Sigo el texto de la reciente edición de la obra: Francisco DE ROJAS ZORRILLA, Casarse por vengarse. Ed. de Linda L. Mullin, Kassel, Edition Reichenberger, 2007. 


\begin{tabular}{|c|c|}
\hline CONDESTABLE & $\begin{array}{l}\text { Aquí esperarle quiero; } \\
\text { ¡ay, Blanca hermosa, por tus soles muero! }\end{array}$ \\
\hline CUATRÍN & $\begin{array}{l}\text { Pon tus potencias y tu vida en salvo; } \\
\text { ven acá, dime, ¿empiezas a ser calvo? } \\
\text { que esta era triste suerte, } \\
\text { y tanto mal se advierte } \\
\text { en un calvino que se ve pelado, } \\
\text { que pesante de estar calaverado, } \\
\text { no hallando lo esmaltado de la pieza, } \\
\text { piensa que se le muere la cabeza. }\end{array}$ \\
\hline CONDESTABLE & $\begin{array}{l}\text { Cualquiera mal tomara } \\
\text { como aqueste volcán no me abrasara. }\end{array}$ \\
\hline CUATRÍN & $\begin{array}{l}\text { ¿Que calvo ser tomaras? mal intento; } \\
\text { óyeme de los calvos este cuento. } \\
\text { Contra el dios Baco cometió un pecado } \\
\text { la mona; pero Baco muy airado, } \\
\text { desde su trono, donde monas salva, } \\
\text { la mona condenó a que fuese calva; } \\
\text { mas apeló la mona la sentencia } \\
\text { al dios Júpiter, y él con más clemencia } \\
\text { licencia dio a la mona que pusiera } \\
\text { la calva en cualquier parte que quisiera; } \\
\text { mas ella la sentencia confirmada, } \\
\text { llamándose infeliz y desdichada, } \\
\text { tanto en su mismo enojo se atropella, } \\
\text { que iba buscando en sí donde ponella; } \\
\text { y, en fin, por no ponérsela en la frente } \\
\text { la puso en el lugar más indecente. } \\
\text { Considera tú, pues, repara ahora, } \\
\text { que el castigo en la mona se mejora, } \\
\text { pues lo que el calvo trae en la mollera, } \\
\text { la mona lo trae puesto en la trasera. }\end{array}$ \\
\hline
\end{tabular}

(vv. 491-522)

\section{Obligados y ofendidos}

Ocupa el quinto puesto en la Primera parte (1640). Habría sido escrita en 1635-1636, según la opinión de diferentes estudiosos ${ }^{15}$. El diálogo entre los criados Beatriz y Crispinillo que interesa está en la segunda jornada. Ella está esperando la llegada del Conde e intenta por todos los medios que él se vaya para que no esté presente. Considera que lo mejor será irritarle con el insulto más grueso que encuentra ${ }^{16}$ :

${ }^{15}$ Ver M. ${ }^{\mathrm{a}}$ Teresa JuLIO, «Obligados y ofendidos, una modélica comedia de capa y espada en busca de puesta en escena», en Felipe PEDRAZA JIMÉNEZ, ed., Doce comedias buscan un tablado. Cuadernos de Teatro Clásico, XI (1999), pp. 192-193.

${ }^{16}$ Sigo el texto de la versión de Fernando Doménech: Madrid, Fundamentos (Clásicos RESAD), 2000. En ella la secuencia de versos de la princeps está respetada en su integridad y puntuada adecuadamente. 
BEATRIZ (Aparte.) (La seña es esta, ¡qué enojo!, del Conde ¿Qué le diré que le irrite?) ¡Calvo!

CRISPINILLO

BEATRIZ

CRISPINILLO

BEATRIZ

CRISPINILLO

BEATRIZ

CRISPINILlO

BEATRIZ

CRISPINILLO
A fe

que diera por serlo un ojo.

¿Calvo?

$\mathrm{Si}$ ser calvo igualo con el bien menos ajeno.

¿Pues qué hay en los calvos bueno? ¿Pues qué hay en los calvos malo? Tu sinrazón se comida y no los quieras culpar: dime ¿habrás visto ahorcar a un hombre calvo en tu vida?

Si sacan a un azotado a visitarle el envés, lo ordinario verás que es un picarote cerrado; que se arrepintió repara un calvo que a Dios negó, mas Judas, que le vendió, tuvo un copete de a vara. Que puede ponerse, arguyo, el calvo en su calavera el cabello de cualquiera, y esotros no más del suyo.

Cuando a un santo que se salva pinta cualquiera pintor, para darle más primor le pinta con tanta calva; y con cuidado y desvelo al contrario has de mirar, que si a un diablo han de pintar, le pintan con tanto pelo...

Calla, que cansada estoy y aun irritada también. Vete, Crispín.

si los alabas me voy.

No era con poca pensión, $\mathrm{y}$ así te puedes quedar: yo no los he de alabar.

Por Dios, que tienes razón, y de enojarte me pesa...

(vv.1329-1369) 


\section{Lo que son mujeres}

Ocupa el primer lugar de la Segunda parte (1645). En un momento de la segunda jornada, Serafina, una de las damas protagonistas, hace ostentación de su éxito en Madrid ${ }^{17}$ :

\section{SERAFINA}

...A mi boca otro menguado dijo (con frialdad no poca):

«Cada labio desa boca es un bocací encarnado».

A mi pelo, sin recelo, dijo un calvo muy de veras, que para hacer cabelleras tenía extremado pelo.

Díjome otro con pasión: «Guardad esos dientes bellos, Serafina, que con ellos me mordéis el corazón».

\section{Entre bobos anda el juego}

La comedia se encuentra en el tercer puesto de la Segunda parte (1645). Fue escrita en 1638. Son dos los episodios, bien conocidos, en los que se producen las menciones ${ }^{18}$.

a) Primera jornada:

\begin{tabular}{|c|c|}
\hline ISABEL & ¿Cómo os llamáis? \\
\hline CABELLERA & Cabellera. \\
\hline ISABEL & ¡Qué mal nombre! \\
\hline CABELLERA & $\begin{array}{l}\text { Pues yo sé } \\
\text { que a todo calvo aficiona. }\end{array}$ \\
\hline ISABEL & $\begin{array}{l}\text { ¿No me diréis qué persona } \\
\text { es don Lucas? }\end{array}$ \\
\hline CABELLERA & Sí diré. \\
\hline ISABEL & ¿Hay mucho que decir? \\
\hline CABELlera & y más espacio quisiera. \\
\hline ANDREA & Tiempo hay harto, Cabellera. \\
\hline CABELlera & Pues atended. \\
\hline
\end{tabular}

${ }^{17}$ Manejo el texto de Comedias escogidas de don Francisco de Rojas Zorrilla. Ordenadas en colección por don Ramón de Mesonero Romanos, Madrid, M. Rivadeneyra, 1861, BAE 54, pp. 191-212. La cita se encuentra en la p. 202, col. a. Como en los demás fragmentos procedentes de esta edición, he prescindido de las letras versales al comienzo de verso.

${ }^{18}$ Op. cit., pp. 11-12 y 65. 
CABellera Don Lucas del Cigarral, cuyo apellido moderno no es por su casa, que es por un cigarral que ha hecho, es un caballero flaco, desvaído, macilento, muy cortísimo de talle, y larguísimo de cuerpo; las manos de hombre ordinario, los pies un poquillo luengos, muy bajos de empeine y anchos, con sus Juanes y sus Pedros; zambo un poco, calvo un poco, dos pocos verdimoreno, tres pocos desaliñado y cuarenta muchos puerco; si canta por la mañana, como dice aquel proverbio, no sólo espanta sus males, pero espanta los ajenos...

(vv. 196-224)

b) Segunda jornada:

Vuelve la cara Cabellera y quiere irse.

LUCAS ¿Qué es yo? Con eso no salva una cuchillada. ¡Fuera! ¡Diga quién es!

CABellera Cabellera, al servicio de tu calva.

LUCAS ¿Qué haces aquí?

(vv. 1461-1465)

5. Sin honra no hay amistad

Se sitúa en cuarta posición en la Segunda parte (1645). En la segunda jornada, Sabañón, estudiante gorrón, cuenta a sus amos don Melchor y don Antonio que doña Juana, la dama a la que pretenden, se burla de ambos ${ }^{19}$.

SABAÑ́n Oye lo que dice.

DON MELCHOR No te creo.

SABAÑón

No me creas.

Que eres rubio, vergonzoso;

que eres calvo, sin modestia;

pues sin cabellera andas

con tu calva a la vergüenza.

Que con tus dos pies se entienden

${ }^{19}$ Comedias escogidas... cit., pp. 295-318. La escena está en p. 306 a. 
los medidores de leguas;

y que con esa toalla

que traes por valona puesta,

la daga de guardamano,

coletón de vara y media,

el sombrerón, la toquilla,

la banda y vueltas francesas,

nadie te digerirá,

porque eres todo crudezas.

\section{Nuestra Señora de Atocha}

En quinto lugar de la Segunda parte (1645). Hay sendas secuencias con alusiones en la segunda y en la tercera jornadas ${ }^{20}$. En la primera, el rey moro Celín le pide al gracioso Limonada, que ha caído cautivo en su poder, que guíe a sus soldados, a lo que accede para salvar la vida. La segunda alusión se encuentra en un intercambio de improperios entre los personajes citados.

a) Segunda jornada:

LiMONADA Cuidadosa centinela
me has de catar en el soto,
que non es mucho que venda
a mi patria por la vida,
que Judas apóstol era
e acompañador de Dios,
e a solas treinta monedas
vendió a Dios, ¿que non fará
un hombre con cabellera?

b) Tercera jornada:

$\begin{array}{ll}\text { CELÍn } & \text { Eres perro, por Mahoma. } \\ \text { LimonAdA } & \text { Por san Pedro, que eres galgo, } \\ & \text { que es santo de Letanía } \\ & \text { e fue santo siendo calvo. }\end{array}$

\section{Los trabajos de Tobías}

Ocupa la séptima posición de la Segunda parte (1645). Son de nuevo dos las secuencias con alusiones, ambas en la segunda jornada. Se refieren a un pobre bobo y calvo que acude llevado por su mujer a que les socorra Tobías en su casa, donde se encuentran con el gracioso Morrión. El gro-

${ }^{20}$ Comedias escogidas... cit., pp. 471-492. Las citas están en pp. 480 c y 486 a. 
tesco portal de pobres que aquí se ofrece constituye uno de los cuadros más peculiares del teatro de Rojas. A Mesonero Romanos debió de pasársele incluir la pieza en su volumen de Comedias escogidas y no se ha publicado en ningún otro lugar, que yo sepa ${ }^{21}$.

a) Primera secuencia:

Sale un pobre tullido en un carretón, que tira una mujer, y el pobre sea calvo.

\begin{tabular}{|c|c|}
\hline MUJER & $\begin{array}{l}\text { Tengan lástima y piedad } \\
\text { del bobo del carretón. }\end{array}$ \\
\hline MORRIÓN & $\begin{array}{l}\text { Llegó el bobo. ¿Qué he de hacer, } \\
\text { que este bobo es mi enemigo? }\end{array}$ \\
\hline & $\begin{array}{l}\text { Maldigo al bobo y maldigo } \\
\text { la boba de su mujer. }\end{array}$ \\
\hline MUJER & $\begin{array}{l}\text { Pues que ya el pelo le deja } \\
\text { a este calvo que así ven, } \\
\text { los calvos piadosos den } \\
\text { a una cabellera vieja. }\end{array}$ \\
\hline MORRIÓN & De ver al bobo me embobo. \\
\hline MUJER & $\begin{array}{l}\text { Al bobo que no ha comido } \\
\text { den su limosna. }\end{array}$ \\
\hline MORRIÓN & $\begin{array}{l}\text { Éste ha sido } \\
\text { el primer calvo que es bobo. }\end{array}$ \\
\hline
\end{tabular}

Salen Tobias y Ana.

$\begin{array}{ll}\text { TOBÍAS } & \text { Ea, pobres míos, llegad. } \\ \text { MORRIÓN } & \text { Ya el santo viejo llegó. } \\ \text { MuJER } & \text { Ya su voz me consoló. } \\ {[\ldots]} & \\ \text { TOBÍAS } & \text { ¿Adónde la llaga ha sido? } \\ \text { MORRIÓN } & \begin{array}{l}\text { Aquí } \text { - sea el lugar salvo-. } \\ \text { Despache a ese pobre calvo, } \\ \text { que es peor que el ser tullido. }\end{array}\end{array}$

$[\ldots]$

MORRIÓn Ay mi pierna, doyla a lobo[s].

TOBías ¿Qué dice, hermano?

MORRIÓN

MUJER No sé.

Váyase el bobo, porque no es mi pierna para bobos.

Deje curársela agora, por el Dios que a todos salva.

${ }^{21} \mathrm{Su}$ edición crítica fue objeto de una tesis doctoral que ha permanecido inédita: Harriet BOYER POWERS, A critical edition of Francisco de Rojas Zorrilla's "Los trabajos de Tobías», Albuquerque, New Mexico, University of New Mexico, 1967. Cito por el texto de la Segunda parte de las comedias de Don Francisco de Rojas Zorrilla, Madrid, Francisco Martínez-Pedro Coello, 1645, Las escenas se encuentran en las pp. $136 \mathrm{v}-137 \mathrm{r}$ y $143 \mathrm{r}$. 
MORRIÓN Váyase a curar la calva de su marido, señora.

b) Segunda secuencia:

$\begin{array}{ll}\text { MORRIÓN } & \begin{array}{l}{[\ldots .]} \\ \text { ¿Qué se hizo el gran bobazo } \\ \text { de su marido? }\end{array} \\ \begin{array}{l}\text { MUJER } \\ \text { MORRIÓN } \\ \text { MUJER }\end{array} & \text { ¿De qué? } \\ \text { CIEGO } & \text { ¿No se le bajó } \\ \text { MUJER } & \text { Grande mal. } \\ & \text { que me hace gran falta, a fe. }\end{array}$

\section{Los tres blasones de España}

En noveno lugar de la Segunda parte (1645). Aunque la comedia tiene la autoría compartida entre Antonio Coello y Rojas Zorrilla, en los versos finales se aclara que a éste le corresponden la jornada segunda, donde se localiza la alusión que interesa, y la tercera. Su escritura debió de producirse antes de 1630, ya que figura entre las ocho piezas vendidas en marzo de 1635 a Diego Logroño ${ }^{22}$. En cada una de las jornadas de esta comedia de santos se dramatiza un tiempo diferente en relación con los patrones de Calahorra, San Emeterio y San Celedonio. La segunda corresponde al asedio de la ciudad por los romanos. Al cónsul Daciano le saca de la cama una visión de Cristo que le deja medio paralizado ${ }^{23}$.

$\begin{array}{ll}\text { CELEDONIO } & \text { ¿A estas horas, Daciano, te levantas? } \\ & \text { En sueños poco ha, con nueva suerte, } \\ & \text { estabas ensayándote a la muerte; } \\ & \text { y tan presto asombrado, } \\ & \text { ¿quieres representarnos lo ensayado? } \\ \text { TORREZNO } & \text { ¿Ah Daciano, hà mi dueño! ¿Qué es aquesto? } \\ & \text { ¿Soñaste que eras calvo? Dilo presto } \\ & \text { Razón tienes, si acaso lo has soñado, } \\ & \text { de marido celoso te has quedado. }\end{array}$

9. Los áspides de Cleopatra

Ocupa el décimo lugar de la Segunda parte (1645). En la primera jornada, la criada Libia se lamenta de que Cleopatra haya prohibido el amor

22 A. Rubio SAN Román y E. Martínez CARro, op. cit.

${ }^{23}$ Comedias escogidas... cit., pp. 545-563. La escena está en la p. 552 c. 
en Egipto, lo que a ella le ha provocado como reacción que sienta amor por todos los hombres, no importa qué problema tengan ${ }^{24}$.

LIBIA $\begin{aligned} & \text { Con dos mil faltas escojo } \\ & \text { a todos, tan torpe soy, } \\ & \text { que tras un tuerto me voy } \\ & \text { porque me hace del ojo. } \\ & \text { Y cuando llegue a faltar } \\ & \text { un tuerto, que querré advierto } \\ & \text { a un calvo, con ser bien cierto } \\ & \text { que no le puedo pelar. } \\ & \text { A un lindo mi tema rara } \\ & \text { le pone ducientos nombres; } \\ & \text { si es feo, digo: los hombres } \\ & \text { no han de tener buena cara... }\end{aligned}$

10. Lo que quería ver el marqués de Villena

En oncena posición de la Segunda parte (1645). Al comienzo de la comedia, el licenciado Cetina le promete a Bermúdez el control de un grupo de estudiantes que le apoyarán para conseguir la cátedra ${ }^{25}$.

Yetina soy su hacedor, y sepa,
que no hay ninguno de cuantos
vienen conmigo, que no
ponga su voto en mis manos.
Todos han de ser sus votos,
y sus reniegos si acaso
pierde la cátedra; y juro,
que si cualquier castellano
negare a vuesa merced,
que haber puede alguno calvo,
ha de hacer Campos con él
cosas que le haga hacer campos.

11. El más impropio verdugo

Ocupa el duodécimo lugar de la Segunda parte (1645). Se representó en la Corte en febrero de 1637. La alusión se encuentra en la tercera jornada ${ }^{26}$.

\footnotetext{
${ }^{24}$ Ibíd., pp. 421-440. Los versos en cuestión están en la p. 425 b.

25 Ibíd., pp. 319-348. La mención está en la p. 319 b-c.

${ }^{26}$ Ibíd., pp. 169-190. Los versos transcritos están en la p. 187 b.
} 
Cosme En fin, ¿vustedes creyeron

DAMIÁN que he de ser verdugo?

COSME

Sí.

CARLOS

COSME

¿Y lo creéis?

Y lo creo.

Pues sea verdugo un calvo destos que andan descubiertos, que los que traen cabelleras tienen vergüenza de serlo. Porque yo ni lo he de ser, ni lo seré ya, ni pienso haberlo sido en presente, en futuro ni en pretérito.

\section{El desafío de Carlos V}

No fue incluida en ninguna de las dos partes del autor. Se ha conservado en un número elevado de sueltas de los siglos XVII y XVIII. Consta su representación en Palacio en mayo de 1635. En la jornada tercera, el gracioso Buscarruido relata ante Carlos $\mathrm{V}$ cómo ha capturado a un supuesto turco que trae prisionero ${ }^{27}$.

BuSCARRUIDO Va de cuento, y va de caso.
Así como me mandasteis,
invicto y piadoso Carlos,
que fuese a caza de turcos,
vengo, iqué hago? tomo y salgo;
salí con una rodela,
con un acerado casco,
mi valor por compañero,
por instrumento mi brazo:
y al campo de Solimán
entré tan determinado,
que parecí ejecutor
que iba a cobrar los salarios.
Echáronme treinta turcos
con sus capotes en caput,
que para ir al cielo, dicen,
que ninguno ha de ser calvo.

\section{Más vale maña que fuerza}

Tampoco fue publicada en las partes de 1640 y 1645 . Ha figurado entre las comedias atribuidas al escritor que se consideraban perdidas hasta la aparición reciente de una edición suelta con características tipográficas del

${ }^{27}$ Ibíd., pp. 407-420. El fragmento está en la p. 418 a-b. 
siglo XVII, aunque sin datos de imprenta. Hay suficientes indicios de la autoría de $\operatorname{Rojas}^{28}$. También hay razones para pensar que se escribió y estrenó en otoño de 1634. Son dos los pasajes con alusiones a calvos, uno en la segunda jornada y otro en la tercera. Ambos se desarrollan con los mismos personajes, los criados Lucrecia y Galón, que despachan con improperios sus desavenencias y sus celos. En el episodio del tercer acto, Galón hace de Lucrecia una pintura de fealdad supina sin saber que es ella misma su interlocutora ${ }^{29}$.

a) Primera jornada:

LUCRECIA Picarazo al quitar, bribón de lance.

Calvo te haré de barba y de bigotes.

GALÓN Antes cien mil azotes

que calvizarme. (¡Ay, Dios! Pondréme en salvo.

Marido cien mil veces y no calvo.

b) Tercera jornada:

LUCRECIA Pues ¿no requiebra muy fino

a una Lucrecia, criada

de Blanca?

GALÓN

¡Qué barbarsimo!

¿Mondonga y Lucrecia? ¿Yo

a Lucrecia? ¡Qué lindo

ajuar para mi punto!

Ya caigo en ella: es un ximio.

Tocarla he visto mil veces,

pues, un moñito postizo

que se pone.

LUCRECIA

GALÓN

¿Hay tal?

\begin{tabular}{ll} 
GALÓN & \multicolumn{1}{c}{ Que es calva } \\
& de canal hasta el ombligo. \\
& Vale un Pirú la mondonga \\
& para tarasca de niños. \\
¿Que es tan fea? & \multicolumn{1}{c}{ Jesús, es } \\
LUCRECIA & el mismo superlativo: \\
& fea, más fea y feísima. \\
& Pudiera servir de grifo \\
& si le pusieran dos alas. \\
& Grifa, calva y ximio han dicho \\
LuCRECIA & que por verla su merced
\end{tabular}

${ }^{28}$ Ver Germán VEGA, «Más vale maña que fuerza...» cit.

${ }^{29}$ Cito por el único ejemplar localizado, que se custodia en la Biblioteca Nacional de España, T-55.272-23. Los pasajes están en B2v b y C4v a-b. He puntuado y modernizado la ortografía. 
no sé por qué pasadizo,

sin ser vellón, diz que estuvo

de hacerle cuartos tantico.

\section{LOS CALVOS DE ROJAS}

Hay que decir en primer lugar que resulta significativa la distribución de las menciones localizadas en los dos tomos del escritor. Por un lado, es llamativa la concentración de bromas sobre calvos que se produce en la Segunda parte (1645): de las doce comedias las hay en nueve, y en tres se encuentran dos casos (textos 3 al 11). Pero, por otro lado, las incluidos en la Primera parte (1640) son las de mayor elaboración y autonomía (textos 1 y 2). La muerte temprana del dramaturgo obliga a considerar una franja temporal relativamente estrecha para la escritura de sus obras; una constricción que sin duda es superior para las del segundo volumen, y factores como el de las burlas contra calvos contribuyen a confirmarlo. La mayoría debió de escribirse con una cercanía clara, lo que refuerza la impresión de que dichas menciones tendrían para el escritor y para el público una intención de complicidad jocosa.

Es claro que en ellas Rojas asume la visión burlesca dominante. En ninguna de las comedias conservadas se permitió los comentarios de discreta y seria contestación que se encuentran en otros escritores afectados, como Cristóbal Suárez de Figueroa o Alonso de Castillo Solórzano. No obstante, sus menciones no carecen de ciertas peculiaridades, ya sea por el aporte de algún detalle que no se registra en los escritores de su momento, ya por la insistencia en otros, ya por la omisión de algunos bien presentes en la época.

Casi todas estas alusiones están en boca de los graciosos respectivos, lo que ya es un indicio de su carácter cómico. La única excepción la ofrece el texto 3, correspondiente a Lo que son mujeres: aquí la referencia, que es la de menor carga satírica de todas las encontradas en Rojas, la hace Serafina, una de las damas protagonistas. Sin embargo, hay que tener en cuenta que al tratarse de una comedia de capa y espada, galanes y damas también asumen los desempeños del humor ${ }^{30}$, y más con los ribetes figuronescos que presenta ésta ${ }^{31}$.

Veamos cuáles son las características principales de las referencias a calvos en el conjunto de sus comedias, con especial insistencia en lo que son sus peculiaridades con respecto al panorama general:

30 Ver Ignacio ARELlano, «La generalización del agente cómico en la comedia de capa y espada», Criticón, 60 (1994), pp. 103-28.

31 R. González Cañal la clasifica entre las «Comedias de costumbres y de figurón» en su estudio sobre «Rojas Zorrilla» (en Javier HuERTA CALvo, dir., Historia del teatro español, Madrid, Ed. Gredos, 2003, I., pp. 1159-1162). 
En bastantes de sus bromas, comparte Rojas con sus coetáneos burlones la idea de que la calvicie es uno de los males o inconvenientes principales que pueden sobrevenir. Las formulaciones extremas mejor conocidas salieron de la pluma de Francisco de Quevedo, el más furibundo y brillante de los anticalvos. Recuérdese la propuesta que formula en su conocido soneto «Calvo que se disimula con no ser cortés» $(528)^{32}-\ll$ Porque la calva oculta quede en salvo, / aventuro la vida: que yo quiero / antes mil veces ser muerto que calvo», y que repite en términos semejantes en varias obras más.

Sin su riqueza imaginativa, Rojas insiste en aludir a la gravedad del problema. En el texto 1 se dice que es peor que el mal de amores, que previamente se ha declarado como el mayor. En el 6b, se apunta como una suerte de contradictio in terminis la posibilidad de ser calvo y santo. En el texto 8, la única explicación que el gracioso encuentra para justificar el estado de frenesí en que han encontrado en plena noche al cónsul es que haya soñado que era calvo. En 13a, el gracioso dice preferir cualquier tormento a quedar de tal guisa. Otros testimonios de esta concepción extremada de todo lo que se relacione con ello se ofrecen en el texto 2, donde calvo aparece como el insulto máximo que se puede proferir; o en el 7 , donde la calvicie es tenida por una enfermedad peor que la de ser tullido; una enfermedad que, según se afirma en el fragmento $7 \mathrm{~b}$, ha sido capaz de acabar con la vida del bobo.

En las burlas de calvos se aprovecharon las múltiples posibilidades de asociar palabras y cosas, sonidos e imágenes, que ofrecía el conceptismo triunfante. Bastantes de estas formulaciones se hicieron tópicas. Las cabezas de los calvos se identificaron con diferentes objetos. A menudo, lo hicieron con vegetales, sobre todo con calabazas - como a propósito del propio dramaturgo aparece en uno de los vejámenes mencionados más arriba-; había para ello razones de homofonía, según muestra a las claras otro vejamen de Pantaleón Rivera dirigido contra un miembro de ese nunca constituido club de los poetas calvos, Alonso Castillo Solórzano: «Relampagueaba sobre todo él una calvaza, o, por mejor decir, una calabaza...» ${ }^{33}$. Los juegos pseudo-etimológicos se fijan asimismo en Calvino. «Si, cual Calvino soy, fuera Lutero, / contra el fuego no hay cosa que me valga» - se dice en otro par de versos del soneto de Quevedo citado (528). También hay un testimonio en el texto 1 de Rojas. Otra de las asociaciones frecuentes es la de calvo y pelar: «No recibe esta casa pobres, ni calvos / porque unos y otros vienen pelados» — se canta en Tanto es lo de más como lo de menos

${ }^{32}$ Los poemas de Quevedo se citan por Poesía orginal completa. Ed. de José Manuel Blecua, Barcelona, Planeta, 1981.

${ }^{33}$ Obras de Anastasio Pantaleón de Rivera. Ed. de Rafael de Balbín Lucas, Madrid, 1944, II, p. 30. 
de Tirso de Molina. En el fragmento del vejamen de Jerónimo de Cáncer citado más arriba hay un caso, y otro rojiano en el texto 9.

Pero la principal asociación es la de la cabeza calva y la calavera: de nuevo se juntan para ello la imagen de los objetos y la fonética de las palabras. En la segunda parte de El caballero puntual de Salas Barbadillo se llega a una formulación contundente, donde de nuevo apreciamos también que es preferible ser muerto que calvo ${ }^{34}$ :

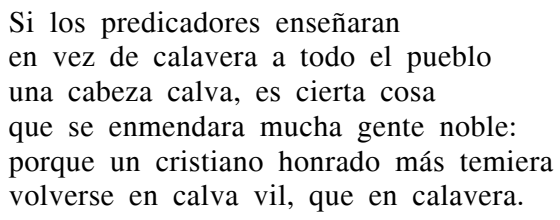

En los textos 1 y 2 de Rojas se da esta asociación calvo-calavera.

Son cuatro los pasajes recopilados de Rojas que hacen referencia al uso de los postizos, motivo importante que se lleva muchas de las pullas de sus contemporáneos. En el texto 4a se apunta la propensión a la cabellera que tienen los calvos — «a todo calvo aficiona». En el texto 7a, se muestra cómo hasta los pobres la requieren y la mujer pide de limosna una «cabellera vieja» para su marido.

De esta afición se hacen eco bastantes textos de esos años. El de $L a$ gallega Mari Hernández de Tirso de Molina resulta curioso de tan traído por los pelos como está ${ }^{35}$ :

$\begin{array}{ll}\text { Álvaro } & \text { Tira una china a esas rejas. } \\ \text { CAldeIRA } & \text { Allá va una china calva } \\ & \text { que, si en la corte estuviera, } \\ & \text { ya se hubiera puesto moño, } \\ & \text { o adoptiva cabellera. }\end{array}$

(vv. 2330-2334)

El postizo es la solución más buscada por los calvos y la más satirizada por los escritores. Pero su uso no fue solo objeto de la atención de estos, también lo fue de los moralistas y hasta de la autoridad competente, que lo consideró entre las cuestiones de orden público, junto con otros usos del vestido y del arreglo personal. Y es que una parte importante de los años de escritura dramática de Rojas Zorrilla coincidieron con los planes reformistas de Olivares, que se preocuparon de estos asuntos. Avanzada la década de los treinta, la ostentación en trajes, adornos, peinados y postizos fue abordada por escritos específicos de hombres de letras como Alonso

${ }^{34}$ Ed. Emilio Cotarelo, Madrid, Tipografía de la Revista de Archivos, 1909, p. 234. 2003.

35 Ed. de Sofía Eiroa, Madrid-Pamplona, Revista Estudios-Universidad de Navarra, 
Carranza, Gutierre Marqués de Careaga o Bartolomé Jiménez Patón ${ }^{36}$. A este último se deben unos Discursos de los tufos, copetes y calvas (Baeza, Juan de la Cuesta, 1639), que suponen una condena terminante de las cabelleras, al tiempo que una descalificación de la calva, exhaustiva y pretendidamente «científica» con profusión de citas de autores religiosos y profanos.

Debe notarse como detalle peculiar que Rojas, tan insistente en sus chistes pelones, no tire nunca sobre uno de los flancos preferidos en la época, el de la «guedeja réquiem» — según expresión acuñada por Quevedo en su soneto al «Calvo que no quiere encabellarse» (527). En efecto, la supuesta procedencia de hombres muertos que se atribuye a los postizos dio lugar a muchas alusiones jocosas, de las que, en cierta manera, puede considerarse culminación la burla urdida en La cabellera y los muertos, un entremés anónimo de la segunda mitad del siglo: cuatro difuntos se le aparecen al protagonista para reclamar los cabellos que componen la peluca que acaba de comprar. En el texto 3, se ofrece la única ocasión en que Rojas trata sobre la cuestión de la procedencia de los postizos: se contempla aquí que sean de vivos.

Por el contrario, hay dos variantes curiosas del tratamiento de los postizos por parte del dramaturgo toledano. En el texto 2 se presenta como una ventaja de los calvos el poder llevar más cabelleras que la propia. Pero más interesante me parece el sesgo que se produce en el texto 5: cuando lo abrumadoramente criticado es el uso de pelucas, por encima de ser calvo, en el pasaje de Sin honra no hay amistad la burla se enfoca hacia quien no la lleva y hace ostentación de su calva: «eres calvo, sin modestia; pues sin cabellera andas / con tu calva a la vergüenza». Sentido parejo apunta el caso de El más impropio verdugo (texto 11).

En cuanto a la física del erial capilar, también parece rasgo genuinamente rojiano esa grotesca apreciación de una calva móvil o expansiva. Asoma en el texto 1 de Casarse por vengarse: Júpiter permite que la mona la desplace por su cuerpo. En el texto $7 \mathrm{~b}$ de Los trabajos de Tobías, el bobo muere porque «se le bajó la calva hasta el espinazo». En el texto $13 \mathrm{~b}$ de Más vale maña que fuerza, se dice de Lucrecia «que es calva de canal hasta el ombligo»; con lo que el carácter indiciario que tiene la presencia de la sátira anticalvos para la atribución a Rojas de esta comedia desconocida hasta hace poco se ve reforzado por las características de su formulación.

Pero los problemas de los calvos no conciernen únicamente a la física o la estética: también corresponden al orden moral. A menudo funciona la

36 Ver Rafael GonZÁlez CAÑAL, «El lujo y la ociosidad durante la privanza de Olivares: Bartolomé Jiménez Patón y la polémica sobre el guardainfante y las guedejas», Criticón, 53 (1991), pp. 71-96. 
ecuación que iguala calvo a vicioso, falso o traidor. Según los Discursos de Bartolomé Jiménez Patón ${ }^{37}$, la calva es una de «las señales más conocidas de afectos viciosos» y aduce opiniones de autores antiguos que la tienen por étimo de calumnia. No es de extrañar que haya quien la considere como marca diabólica: «echaba fuego por los ojos y olía a azufre; era calvo y ceceoso; todas señales de diablo»-describe Francisco Bernardo de Quirós ${ }^{38}$. Sin embargo, los diablos de Rojas Zorrilla tienen mucho pelo, como se señala decididamente en su defensa burlesca de los calvos en Obligados y ofendidos (texto 2): «si a un diablo han de pintar, / le pintan con tanto pelo...».

De las tachas morales imputadas a los calvos, en las comedias del escritor toledano se asume el de la traición. En el texto 10, calvo es sinónimo de traidor. En el 6, se expresa con contundencia: si Judas vendió a Dios, «¿qué no fará un hombre con cabellera?». Sin embargo, también comparece Judas en el texto 2 donde con su «copete de a vara» se le contrapone al calvo San Pedro. Por cierto, también son dos las ocasiones en que se alude al apóstol. Nótese la correspondencia que tienen estas alusiones con el fragmento del vejamen académico del propio escritor visto anteriormente. En el texto $6 b$, se pone el énfasis en la rareza de ser santo y calvo. Lo que, de alguna manera, guarda relación con que en el texto 12 se bromee con la supuesta exigencia entre los moros de no ser calvos para ir al cielo.

Como se apuntó, en las dos obras de la Primera parte se encuentran las incursiones más específicas y morosas de Rojas en el tratamiento satírico de los calvos. El resto de las presencias alopécicas en sus comedias no dan pie a parlamentos específicos, sino que se formalizan en alusiones al hilo de otros asuntos. Pero que, en todo caso, muestran con su acumulación el peso que el tema satírico tenía en la mente del autor. En las dos piezas publicadas en 1640 se nota una voluntad de sacar el tema a colación premeditadamente sin que lo exijan las circunstancias. Veamos estos episodios con más detalle.

En el de Casarse para vengarse (texto 1), el Condestable dice morir por amor y que aceptaría cualquier otro mal, incluso ser calvo; a lo que le replica su criado Cuatrín decidido a mostrarle la superioridad de la calvicie como problema. Para ello aduce el cuento de Baco y la mona, que sin duda es gracioso y está bien contado, pero que no parece venir a cuento de lo que se plantea. En el panorama de chistes sobre calvos muestra cier-

${ }^{37}$ Discursos de los tufos, copetes y calvas, Baeza, Juan de la Cuesta, 1639. Ed. de Abraham Madroñal, Madrid, Real Academia Española, 2003, fol. 3v (Consultado en Corde, marzo de 2007).

${ }_{38}$ Aventuras de don Fruela. Ed. Celsa Carmen García Valdés, Madrid, Instituto de Estudios Madrileños, 1984, p. 173. 
ta originalidad. No he podido localizar la fuente de donde lo toma, si es que no se trata de una invención del escritor. Lo que sí es claro es que bastantes de sus componentes participan de tradiciones previas. Es el caso de los protagonistas de la fábula. Por la asociación de Baco y la mona se pregunta la protagonista en La pícara Justina: «¿Mas que no sabéis por qué pintó Apeles a Ceres, diosa del pan, con un perrillo de falda, y a Baco, dios del vino, con una mona?» ${ }^{39}$. De las afinidades de la mona con el vino, cuyo dios es Baco, se hace eco el Tesoro de Covarrubias: «estas monas apetecen el vino y las sopas mojadas en él, y hace diferentes efetos la borrachez en ellas [...] De aquí vino llamar mona triste al hombre borracho que está melancólico y callado, y mona alegre al que canta y bayla, y se huelga con todos». También de la asociación de la calva con la «trasera» se pueden alegar testimonios, como el del soneto de Quevedo citado anteriormente (527): «háseme vuelto la cabeza nalga: / antes greguescos pide que sombrero».

El episodio de Obligados y ofendidos (texto 2) dispone también de cierta autonomía, aunque está mejor traído a cuento que la anécdota anterior. Aparentemente ofrece la única defensa de los calvos — «¿Pues qué hay en los calvos malo?»— del teatro de Rojas, pero es marcadamente jocosa. Bien podría haber tenido origen en un ejercicio de academia. El hecho de que ni la acción ni el sentido justifiquen su inclusión contribuye a pensar en ello. Su sentido cómico se ve subrayado por suficientes factores, desde el estar puesta en boca del gracioso al contexto en el que se produce: resulta que Beatriz, la criada de Fénix, aguarda al Conde e intenta por todos los medios que el pesado del criado deje de enrollarse con cualquier excusa y se vaya de una vez. De suerte que, cuando efectivamente tiene constancia de que ya está ahí el que espera, intenta echar el resto para conseguir que la deje sola. Y le llama calvo. Pero ni con esas, ni con el peor de los insultos - así debe entenderse su inclusión en ese momento- Crispinillo pierde su capacidad de decir lo que sea para estorbar: es capaz del colmo de defender lo indefendible, a los calvos. Lo que diga, por tanto, moverá a risa al público sin que se tome en serio los argumentos esgrimidos; argumentos que, por otra parte, mezclan motivos de cierta objetividad (los casos de Judas y San Pedro) con los de pura broma (la posibilidad de usar cualquier cabellera). Al final, Crispinillo termina por dar la razón a Beatriz, que no ha querido alabar a los calvos. De todas formas, el humor de las palabras y de la situación no tapan del todo el esfuerzo autocomplaciente del dramaturgo calvo por replicar a los tópicos sobre las taras físicas y morales de los de su condición.

${ }^{39}$ Francisco LóPez de ÚBEDA, La pícara Justina. Ed. Antonio Rey Hazas, Madrid, Editorial Nacional, 1977, I, pp. 274-275. Ver Antonio REY HAZAS, «El bestiario emblemático de La pícara Justina», Edad de Oro, XX (1999), pp. 136-137. 
Seguro que Rojas también disfrutó en lo personal con la cuña que puso en boca del gracioso Morrión en el contexto también jocoso - grotesco, más bien- del episodio de Los trabajos de Tobías (texto 7a): «Éste ha sido el primer calvo que es bobo». Es evidente que no se puede ser al mismo tiempo astuto (engañador, traidor, etc.) y bobo: es, por tanto, una astuta manera de dar vuelta a los principales defectos que desde antiguo se imputaban a los calvos. 